\title{
Breakfast consumption among Saudi primary-school children relative to sex and socio-demographic factors
}

\author{
Hazzaa M. Al-Hazzaa ${ }^{1 *}$ D, Abdulrahman M. Alhowikan², Maha H. Alhussain ${ }^{3}$ and Omar A. Obeid ${ }^{4}$
}

\begin{abstract}
Background: Breakfast is an important meal that provides essential nutrients and energy. However, few comprehensive studies have reported breakfast habits and related behaviors among Saudi children. This study investigated breakfast consumption patterns and the associations of socio-demographic variables with daily breakfast intake among Saudi children.

Methods: A multistage stratified cluster random sampling technique was used to select 1051 elementary school boys and girls in Riyadh. Body weight and height were measured and body mass index (BMI) was computed. The breakfast eating habits and behaviors were assessed using a specifically designed self-reported questionnaire that was completed by the children's parents.

Results: More than $79 \%$ of children skipped daily breakfast, with no significant sex difference. Children in private schools consumed breakfast more frequently than those attending public schools. Multivariate analyses showed that boys in private schools had a significantly higher intake of breakfast than that in boys in public schools, yet, boys in public schools had significantly higher BMI than boys in private schools. Using logistic regression while adjusting for confounders showed insignificant effect for parent education. Among breakfast eaters, spread cheese sandwiches were consumed most frequently, followed by fried egg sandwiches and breakfast cereals. Full-fat milk, tea with milk, water, and fruit juice were the most consumed drinks. Girls consumed significantly more fresh fruits during breakfast than did boys. Mothers prepared breakfast at home most of the time (84.5\%). Parents appeared mostly satisfied with the breakfast consumed by their child at home and placed high importance on breakfast compared to lunch or dinner.

Conclusions: The proportion of school children who ate daily breakfast at home was low, which may have implications for children's school performance. Effort is needed to promote daily breakfast consumption among Saudi school children and to introduce appropriate interventions aimed at promoting daily breakfast consumption among Saudi children.
\end{abstract}

Keywords: Breakfast, Children, Gender, Skipping breakfast, Saudi Arabia, Socio-demographic factors

\footnotetext{
* Correspondence: halhazzaa@hotmail.com

'Lifestyle and Health Research Center, Health Science Research Center,

Princess Nourah bint Abdulrahman University, P. O. Box: 93216, Riyadh

11673, Saudi Arabia

Full list of author information is available at the end of the article
}

(c) The Author(s). 2020 Open Access This article is licensed under a Creative Commons Attribution 4.0 International License, which permits use, sharing, adaptation, distribution and reproduction in any medium or format, as long as you give appropriate credit to the original author(s) and the source, provide a link to the Creative Commons licence, and indicate if changes were made. The images or other third party material in this article are included in the article's Creative Commons. licence, unless indicated otherwise in a credit line to the material. If material is not included in the article's Creative Commons licence and your intended use is not permitted by statutory regulation or exceeds the permitted use, you will need to obtain permission directly from the copyright holder. To view a copy of this licence, visit http://creativecommons.org/licenses/by/4.0/ The Creative Commons Public Domain Dedication waiver (http://creativecommons.org/publicdomain/zero/1.0/) applies to the data made available in this article, unless otherwise stated in a credit line to the data. 


\section{Background}

Breakfast is an important meal of the day, providing essential nutrients to support normal growth and re-fueling energy after long hours of sleep [1]. In addition, breakfast consumption can improve cognitive learning and academic performance [2-6]. In contrast, skipping breakfast in adolescents is associated with less healthy behaviors such as lower physical activity levels [7] and poorer food choices [1]. Moreover, family environment and structure have been shown to influence breakfast behaviors. Children living with both parents were more likely to consume breakfast compared to those living with a single parent [8, 9]. Furthermore, a study with a large number of adolescents from ten European cities reported that the factors most associated with breakfast consumption included girls with highly educated mothers, boys with traditional families, boys encouraged by their parents, and girls whose peers ate healthy diets [10]. Barriers to breakfast consumption are diverse; however, among elementary school children in Bangkok, the key barriers were lack of time, waking late, and no breakfast prepared at home [11].

Skipping breakfast predisposes children to obesity. In the United States, adolescents who consumed breakfast more often had a lower body mass index (BMI) than that in those who skipped breakfast [12]. It has been estimated that skipping daily breakfast among Canadian pre-school children nearly doubled their chances of being overweight [13]. Childhood obesity was also associated with those who, over the long-term, skipped breakfast and who consumed bread and sugar-sweetened drinks rather than fruits and vegetables [14, 15]. Moreover, a recent meta-analysis involving 106,935 participants revealed that skipping breakfast was associated with a significantly increased risk of developing type 2 diabetes mellitus [16]. In addition, skipping breakfast affects the adequacy of nutrient intake. A multicenter European study involving a large number of adolescents aged 12. 5-17.5 years from ten cities found lower vitamin D and vitamin C concentrations in boys and girls who skipped breakfast compared to those who ate breakfast [17].

Not only having breakfast but also the type of breakfast may be of significant importance in meeting nutritional needs. A large body of epidemiological research has consistently reported that higher consumption of ready-to-eat (RTE) cereals by children is more likely to meet their recommended nutrient intakes [18-20]. Breakfast cereal consumption was associated with higher dietary vitamins and mineral intake and healthy eating index and was not related to increased total energy or sodium intakes [21]. However, breakfast consumption of RTE cereals may contain low or high amounts of sugar with the latter case of nutritional concern. A randomized experiment revealed that high-sugar cereals increased children's total sugar consumption and reduced the overall nutritional quality of their breakfast when compared to serving low-sugar cereals and that children were more likely to consume lowsugar cereals when provided with fruits, which is considered a healthier breakfast choice [22].

Although breakfast is well-recognized for its benefits for the well-being of children, insufficient studies have been conducted on breakfast habits and related behaviors among Saudi school children and adolescents [23-26]. Earlier breakfast findings in Saudi children revealed a low percentage of breakfast skippers $(23,24)$; however, these studies were conducted two decades ago. Furthermore, a large epidemiological study involving Saudi adolescents from three urban cities (Riyadh, Jeddah, and Al-Khobar) found that only $28.7 \%$ of boys and $20.6 \%$ of girls had daily breakfast intake [25]. Indeed, the proportion of breakfast skippers among Saudi adolescents appears much larger than the estimated 10-30\% reported worldwide [27]. Factors associated with breakfast skipping among Saudi adolescents include higher BMI and waist to height ratio [28] and inadequate sleep duration [29]. The differences between boys and girls in food and beverage choices for breakfast meals were investigated among young Saudis aged $12-18$ years in the Al Qassim region [26]. The findings indicated that boys had healthier choices and skipped breakfast less often than did girls. Additionally, girls in schools ate sandwiches, pizza, chips, and cookies for breakfast more often than boys did, whereas boys more frequently drank milk and juice in school than did girls [26].

It is evident from the above-mentioned studies that breakfast consumption is an important and healthy dietary habit and that skipping breakfast is an unhealthy eating lifestyle with negative influences on child health, wellbeing, and academic and cognitive performance. However, although we have some knowledge about Saudi adolescent's breakfast habits, data on breakfast habits and associated behaviors in young children are insufficient, despite recent massive lifestyle and nutritional transitions among Saudi children and adolescents. Therefore, the purpose of the present study was to investigate the breakfast consumption patterns, including foods and beverage choices and preferences, and to examine the associations of sociodemographic variables and BMI with daily breakfast intake among Saudi children attending elementary schools in Riyadh.

\section{Methods}

\section{Sample size and sampling technique}

This cross-sectional study was conducted in Riyadh city from March to May 2017. Detailed sampling information have been published elsewhere [30]. Briefly, the study included Saudi children enrolled in primary schools (grades 1-6), who did not suffer from any medical condition that was related to eating disorders or allergy to foods. Participants' selection was based on a multistage 
stratified cluster random sampling technique. Stratification was based on geographical areas (east, west, north, and south) and boys' and girls' schools. Within each geographical area, schools were randomly selected and classes were chosen randomly from each of the six grades. Invitation to participate in the study was then given to every student in the chosen classes. The sample size was computed with a population proportion equal 0.50 , with a confidence level of $95 \%$ and a margin of error of 5\%. Further, to account for any missing data, non-responders, and the clustered design effect, additional $20 \%$ of participants were added to the computed sample size. Thus, the final sample size become 920 boys and girls.

There are normally about 25 Saudi students in each class in public schools and nearly 15 Saudi students in each class in private schools. Data were collected from 12 elementary schools in the city of Riyadh with 72 classes, randomly located in the four geographical areas of the city (east: 2 schools [12 classes] from each of boys' and girls' schools; west: one [ 6 classes] boy's school and one [ 6 classes] girl's school; north: 2 schools [12 classes] from each of boy's and girl's schools; south: one [6 classes] boy's school and one [6 classes] girl's school). Trained research assistants collected the data with supervision from two of the main investigators. After obtaining consent forms from parents, weight and height were measured at schools by the research assistants and the returned questionnaires from parents were collected from the students in school.

\section{Ethical considerations and institutional review board (IRB) approval}

The IRB of King Saud University approved the study (17/0064/IRB). The research procedures were consistent with the principles expressed in the Declaration of Helsinki. Data confidentiality was ensured by coding and storage in restricted access files. The children and their parents were free to withdraw from the study at any time if they expressed unwillingness to answer the questionnaire. Approval to conduct this study in primary schools was obtained from the directorate of schools at the Ministry of Education and the principals of the selected schools. In addition, written informed consent was obtained from all parents.

\section{Anthropometric measurements}

Anthropometric measurements included body weight and height of the children as well as the calculated body mass index (BMI). Measurements were performed in the morning by a trained researcher according to written standardized procedures. Body weight was measured to the nearest $100 \mathrm{~g}$ using calibrated portable medical scales (Seca, Germany). All measurements were conducted with minimal clothing and without shoes. Height was measured to the nearest centimeter using a calibrated measuring rod while the subject was in a full standing position without shoes. BMI was calculated as the ratio of weight in kilograms divided by the squared height in meters.

\section{Breakfast eating habits and behaviors}

The breakfast eating habits, food choices, and behaviors were assessed using a specifically designed self-reported questionnaire that was completed by the children's parents (see supplementary file entitled Additional file 1). In addition, the questionnaire included information on father's and mother's ages, father's and mother's educational levels, family income, and type of housing. Moreover, parents were asked who prepared breakfast for the child, how satisfied they were with the breakfast consumed by the child, how important they felt the breakfast meal was for their child, and if they believed the breakfast meal was important for their child's academic performance. Other questions were related to breakfast choices and behaviors. Breakfast food choice was defined as what the child chose to eat to break their fast at home or on their way to school or at school from early morning until 10 am during school days and from early morning until $11 \mathrm{am}$ on weekends. A variety of common breakfast choices of were provided in the questionnaire including egg, cheese, peanut butter, or hummus sandwiches; pizza; ready-to-eat cereals; potato; sausage; cookies; or muffins. Parents were also asked to answer questions based on the child's usual dietary habits in a typical week. The questionnaire was reviewed and agreed upon by three experts in the field of nutrition and dietary habits.

\section{Data and statistical analysis}

Data were entered into a data file, checked, cleaned, and analyzed using IBM SPSS Statistics for Windows, version 22.0. Descriptive statistics were reported as means and standard deviations. Categorical variables were reported as proportions and Chi-square tests. Differences between boys and girls in anthropometric measurements were tested using t-tests for independent samples. The differences in breakfast intake per week relative to sex and school type were compared by two-way analysis of covariance (ANCOVA) while controlling for age. Logistic regression analysis was also used to test the associations of sociodemographic variables with daily versus nondaily breakfast intake. Finally, we used two-way multivariate analysis of covariance (MANCOVA) to examine differences in average breakfast intake and BMI as stratified by sex and school type while controlling for several sociodemographic factors (child's age, father age, mother age, father education, mother education, family income, and housing size) and we included BMI as an outcome to check if the interaction effect between sex and school type was independent of BMI differences between boys 
and girls in public versus private schools. The Bonferroni test was used to test for between-subject effects. The alpha level was set at 0.05 and $p$-values less than the alpha level were considered significant.

\section{Results}

The final number of participants was 1051 children (523 boys and 528 girls) between the ages of 5.9 and 13.4 years, with a mean age of 9.2 years, which was similar between boys and girls. The response rate by the parents was 94.5\%. Students coming from public schools represented two-thirds of the participating sample. Parents answering the questionnaire appeared to have no problems with the phrases used in the questionnaire, as evident by their high response rate and lack of comments regarding the clarity of the questions on the returned questionnaires.

Analysis of the demographic characteristics of the participants (not shown in tables) indicated significant $(p<0.001)$ differences in parent's responses between boys' and girls' schools. Fathers answered more boy school's questionnaires than did mothers (51.3\% versus $33.5 \%$ ) whereas mothers answered more girl school's questionnaires than did fathers (59.5\% versus 43.8$)$. On average, fathers were older than mothers and a higher percentage of them had postgraduate degrees. However, mothers had a higher percentage of college degrees than that of fathers. In addition, approximately $50 \%$ of the parents' incomes ranged between 5001 and 15,000 Saudi Riyals (1334-4000 US\$).

Table 1 presents the descriptive characteristics of the participants, average breakfast intake per week, and the proportion of children with daily breakfast intake, stratified by sex and school type. Boys were significantly $(p<0.001)$ heavier and had a significantly $(p<0.001)$ higher BMI. The average breakfast consumption by the children was 3.51 days per week with no significant difference between boys and girls. However, there was a significant $(p=0.001)$ sex by school interaction in average breakfast intake. The proportion of daily breakfast intake was almost $21 \%$, with no significant difference in the proportions of boys and girls consuming daily breakfast (19.3\% versus $22.1 \%)$. However, a significantly higher proportion of girls in public schools (21.4\%) had daily breakfast intake compared to that in boys $(13.3 \%)(p=0.005)$, whereas a significantly higher proportion of boys in private schools ate daily breakfast compared to boys in public schools $(32.5 \%$ versus $13.3 \%, p<0.001)$. Moreover, twoway ANOVA (not shown in Table 1) revealed no significant difference in breakfast intakes (days per week) between boys and girls relative to age categories or child's living status (living with both parents, with father, with mother, or with a relative). The results also showed no significant differences between boys and girls in breakfast intakes during weekdays $(p=0.601)$ or weekends $(p=0.154)$. However, there was more adherence to daily breakfast intake on weekends (41.3\%) than on weekdays (28.9\%).

The types of breakfast choices (\%) consumed at home by Saudi children relative to sex are shown in Table 2. A variety of foods were consumed during breakfast by the Saudi children. Spread cheese sandwiches (42.2\%) were consumed most frequently, followed by fried egg sandwiches (41.1\%), breakfast cereals (34.3\%), and boiled egg sandwiches (27.1\%). Among the kind of cereals consumed at breakfast, cornflake cereals were predominant (23.6\%). Cereals such as bran with honey and nuts or oat cereals were consumed least frequently. Less healthy foods such as donuts, hot dogs, hamburger, cookies, biscuits, and French fries were minimally consumed (2.4$4.5 \%)$. In general, the majority of children seemed to prefer their breakfast in the form of sandwiches. There were significant differences in eating patterns between boys and girls. There were also significant differences between boys and girls in their preferences for breakfast.

Table 1 Descriptive characteristics of the participating children

\begin{tabular}{|c|c|c|c|c|}
\hline Variable & Boys $(N=523)$ & Girls $(N=528)$ & All $(N=1051)$ & $p$-value ${ }^{a}$ \\
\hline Age (years) & $9.3 \pm 1.7(9.16-9.45)$ & $9.2 \pm 1.7(9.06-9.35)$ & $9.2 \pm 1.7(9.10-9.30)$ & 0.165 \\
\hline Body weight (kg) & $38.6 \pm 23.2(36.6-40.6)$ & $33.2 \pm 12.9(32.9-34.3)$ & $35.8 \pm 18.9(34.7-36.9)$ & $<0.001$ \\
\hline Body height $(\mathrm{cm})$ & $133.6 \pm 11.7(132.6-134.6)$ & $133.1 \pm 12.5(132.0-134.2)$ & $133.4 \pm 12.1(132.7-134.1)$ & 0.517 \\
\hline Body mass index (BMI) & $20.8 \pm 9.6(20.0-21.6)$ & $18.1 \pm 4.4(17.7-18.5)$ & $19.4 \pm 7.6(18.9-19.9)$ & $<0.001$ \\
\hline Average breakfast intake (day/week) & $3.44 \pm 2.3(3.24-3.64)$ & $3.58 \pm 2.3(3.38-3.78)$ & $3.51 \pm 2.3(3.37-3.65)$ & 0.350 \\
\hline Public school & $3.07 \pm 2.2(2.88-3.26)$ & $3.52 \pm 2.3(3.32-3.72)$ & $3.30 \pm 2.3(3.16-3.44)$ & \multirow{2}{*}{$\begin{array}{l}\text { Gender by school } \\
\text { interaction }=0.001\end{array}$} \\
\hline Private school & $4.23 \pm 2.3(4.03-4.43)$ & $3.68 \pm 2.3(3.48-3.87)$ & $3.95 \pm 2.3(3.81-4.09)$ & \\
\hline Daily breakfast intake (\%) & 19.3 & 22.1 & 20.7 & 0.285 \\
\hline Public school & 13.3 & 21.4 & 17.3 & 0.005 \\
\hline Private school & 32.5 & 23.6 & 27.9 & 0.070 \\
\hline$p$-value & $<0.001$ & 0.736 & $<0.001$ & \\
\hline
\end{tabular}

Data are means \pm standard deviations $(95 \% \mathrm{Cl})$ or percentage

${ }^{a}$ T-test for independent samples (anthropometrics), 2-way ANCOVA (with average breakfast intake (day/week) as adjusted for age) or Chi Squares tests for the proportions (daily breakfast intake (\%)) 
Table 2 Types of breakfast (\%) usually consumed by Saudi children relative to gender (more than one choice was possible)

\begin{tabular}{lllll}
\hline Variable & Boys & Girls & All & $\boldsymbol{p}_{\text {-value }}$ \\
\hline Spread cheese sandwich & 39.2 & 45.3 & 42.2 & $\mathbf{0 . 0 4 6}$ \\
Fried egg sandwich & 45.1 & 37.1 & 41.1 & $\mathbf{0 . 0 0 8}$ \\
Breakfast cereals & 30.2 & 38.4 & 34.3 & $\mathbf{0 . 0 0 3}$ \\
Boiled egg sandwich & 27.5 & 26.7 & 27.1 & 0.762 \\
Nutella sandwich & 16.6 & 23.5 & 20.1 & $\mathbf{0 . 0 0 6}$ \\
Tuna sandwich & 13.6 & 20.1 & 16.8 & $\mathbf{0 . 0 0 5}$ \\
Fava beans (Foul) & 17.0 & 14.4 & 15.7 & 0.242 \\
Labneh sandwich b & 10.5 & 17.8 & 14.2 & $\mathbf{0 . 0 0 1}$ \\
Croissant & 9.9 & 11.6 & 10.8 & 0.399 \\
Cheese pie (Fataer Jubin) & 9.8 & 10.4 & 10.1 & 0.367 \\
Thyme sandwich & 6.9 & 11.2 & 9.0 & $\mathbf{0 . 0 1 5}$ \\
Peanut butter sandwich & 8.0 & 10.0 & 9.0 & 0.256 \\
Falafel sandwich & 7.5 & 6.1 & 6.8 & 0.367 \\
Jam sandwich & 7.1 & 5.1 & 6.1 & 0.184 \\
Pancake & 4.6 & 7.2 & 5.9 & 0.073 \\
Solid cheese sandwich & 5.0 & 6.6 & 5.8 & 0.251 \\
Labneh pie (Fataer Labneh) & 4.0 & 6.4 & 5.2 & 0.078 \\
Thyme pie (Fataer Zatar) & 3.8 & 6.4 & 5.1 & 0.055 \\
Mortadella sandwich & 4.0 & 5.2 & 4.7 & 0.322 \\
Yogurt-with or without fruits & 2.9 & 6.3 & 4.6 & $\mathbf{0 . 0 0 9}$ \\
Oreo biscuit/other types of biscuit & 4.4 & 4.5 & 4.5 & 0.908 \\
Donuts & 2.7 & 4.4 & 3.5 & 0.140 \\
Pizza & 3.3 & 3.6 & 3.4 & 0.756 \\
Hot dog & 3.6 & 3.0 & 3.3 & 0.586 \\
Hamburger & 3.4 & 2.1 & 2.8 & 0.179 \\
Cake or cookies & 2.7 & 2.8 & 2.8 & 0.871 \\
Chickpeas (Hummus) sandwich & 2.7 & 2.3 & 2.5 & 0.673 \\
Other kinds of breakfast & 2.3 & 2.4 & 0.821 \\
\hline Chi Squas & 5.1 & 4.0 & 0.063 \\
\hline
\end{tabular}

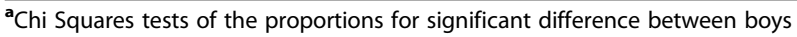
and girls

${ }^{\mathrm{b}}$ Soft, cream cheese made from strained yogurt, popular in Middle Eastern cuisine

Some popular Mediterranean breakfast choices like fava beans (Foul), Labneh sandwich, thyme sandwich, and falafel sandwich were fairly consumed by children as breakfast. Additionally, traditional foods such as sweet Arabic pastries, dates, or Marase'a (home-made wheat bread) was were not often eaten by children at breakfast time. Furthermore, children in public school consumed significantly more spread cheese sandwiches than those in private schools (44.7 versus 37.1), whereas children in private schools seem to prefer to breakfast cereals (40.9\% versus $31.2 \%)$, Nutella sandwich $(24.4 \%$ versus $17.9 \%)$, Falafel sandwich (fava beans) (8.8\% versus $5.8 \%$ ), and pancakes (7.9\% versus $4.9 \%)$ compared to children in public schools.

Table 3 shows breakfast intake preferences at home among Saudi children relative to sex. Most (71.5\%) boys and girls preferred to consume breakfast cereals with sugar, while a much smaller proportion (18.0\%) preferred cereals with fruits, without any significant difference between boys and girls. In addition, a higher percentage of girls $(49.6 \%)$ than boys $(43.2 \%)$ consumed fresh fruit at breakfast. Apple consumption (21.8\%) came first, followed by banana (21.2\%), orange (13.5\%), and grapes (11.0\%), with girls consuming more apples and grapes compared to that in boys. Furthermore, most children (97.1\%) consumed drinks during breakfast time. Full-fat milk (40.8\%), tea with milk (34.5\%), water (29.9\%), and fruit juice (24.4\%) were the drinks most consumed by the children. Girls showed significantly $(p=0.014)$ higher water intake at breakfast than that in boys.

Table 4 shows the timing of breakfast consumption and parent's perception of their child's daily or non-daily breakfast intake. There was no significant difference in daily breakfast frequency between children consuming breakfast before or after 6:00 am (schools start at 7:00 am). In addition, mothers and domestic helpers prepared breakfast 85 and $8.6 \%$ of the time, respectively. More than $40 \%$ of the parents were very satisfied with their children' breakfast intake. Daily intake of breakfast was significantly higher among the children of parents who were very satisfied with their children' breakfast $(p=$ 0.004). In addition, parents placed high importance (91.2\%) on the breakfast intake of their children. However, this was not significantly reflected in daily breakfast intake. Compared to lunch and dinner, $80.0 \%$ of the parents considered breakfast to be the most important meal of the day for their children. The children of parents with strong opinions on breakfast as a meal were more likely to have daily breakfast intake. Also, nearly $74 \%$ of the parents considered having enough protein in their children's breakfast to be very important. Furthermore, 93\% of parents believed that eating breakfast improved their child's academic performance. However, this did not influence the breakfast intake of the children.

Additionally, there was a low percentage (nearly 1\%) of lactose intolerance among the children, with more boys $(1.6 \%)$ than girls $(0.2 \%)$ having this nutritional disorder. The three most common reasons for the lack of regular breakfast at home were not feeling hungry (nearly $50 \%$ ), waking late (21.2\%), and no time to eat breakfast at home but provided money to buy food at school (17.1\%). The main types of sandwiches eaten by children on their way to schools were egg (45.3\%) and cheese (nearly 35\%) sandwiches.

Table 5 presents the socio-demographic characteristics of the participants stratified according to daily or non- 
Table 3 Breakfast intake preferences by Saudi children relative to gender (more than one choice was possible)

\begin{tabular}{|c|c|c|c|c|}
\hline Variable & Boys & Girls & All & $p$-value ${ }^{a}$ \\
\hline Preference for cereal with/without added sugar (\%) & & & & 0.374 \\
\hline With added sugar & 72.9 & 70.1 & 71.5 & \\
\hline Without added sugar & 27.1 & 29.9 & 28.5 & \\
\hline Preference for cereal with or without fruit (\%) & & & & 0.439 \\
\hline With fruit & 16.8 & 19.1 & 18.0 & \\
\hline Without fruit & 83.2 & 80.9 & 82 & \\
\hline Percentage of fresh fruit eaten with breakfast (\%) & 43.2 & 49.6 & 46.4 & 0.037 \\
\hline \multicolumn{5}{|l|}{ Types of fruits most consumed with breakfast (\%): } \\
\hline Apple & 18.0 & 25.6 & 21.8 & 0.003 \\
\hline Banana & 19.1 & 23.3 & 21.2 & 0.098 \\
\hline Orange & 12.8 & 14.2 & 13.5 & 0.509 \\
\hline Grape & 9.0 & 13.1 & 11.0 & 0.035 \\
\hline Pear & 3.1 & 5.7 & 4.4 & 0.038 \\
\hline Strawberries & 2.5 & 5.7 & 4.1 & 0.009 \\
\hline Percentage of drinks consumed with breakfast (\%) & 98.1 & 96.0 & 97.1 & 0.048 \\
\hline Types of drinks most consumed with breakfast (\%): & 0.4 & 0.8 & 0.6 & 0.420 \\
\hline Full fat milk & 42.3 & 39.4 & 40.8 & 0.345 \\
\hline Tea with milk & 34.4 & 34.7 & 34.5 & 0.934 \\
\hline Water & 26.4 & 33.3 & 29.9 & 0.014 \\
\hline Fruit juice & 22.0 & 26.7 & 24.4 & 0.075 \\
\hline Tea & 13.2 & 12.3 & 12.7 & 0.668 \\
\hline Fruit drink & 7.3 & 8.3 & 7.8 & 0.519 \\
\hline Low fat milk & 4.8 & 9.3 & 7.0 & 0.004 \\
\hline Soft drink (soft beverage) & 5.9 & 1.7 & 3.8 & $<0.001$ \\
\hline
\end{tabular}

${ }^{\mathrm{a} C h i}$ Squares tests of the proportions for significant difference between boys and girls

daily breakfast intakes (\%). There were no significant differences in many variables between children consuming daily or non-daily breakfast. However, there were significant differences between daily versus non-daily breakfast consumers in father's education $(p<0.001)$, mother's education $(p=0.004)$, and family income $(p=0.001)$, with a clear positive trend between daily breakfast intake and increasing father education, mother education, and family income.

Table 6 displays the results of logistic regression analysis adjusted for age, weight, and BMI for selected sociodemographic variables relative to daily versus nondaily breakfast intake. Only age was a significant covariate, as well as mother age of less than 30 years and 50 59 years. Father's education, mother's education, and family income, which were significant influencing factors of daily breakfast intake in Table 5 , were insignificant in the logistic regression analysis.

The results of two-way MANCOVA for average breakfast intake and BMI stratified by sex and school type while controlling for socio-demographic factors are shown in Table 7 . The findings indicated that sex was significant $(p<0.001)$, whereas school type was not $(p=0.070)$. However, the sex by school type interaction effects for breakfast intake were significant $(p<0.001$. Boys in private schools had higher breakfast intake than that in girls, whereas girls in public schools had higher breakfast consumption than that in boys; however, boys in public but not in private schools were significantly heavier than girls.

\section{Discussion}

This comprehensive study investigated breakfast habits and related behaviors among Saudi children in primary schools in Riyadh using a sufficient and representative sample randomly chosen from both public and private schools within the large metropolitan city of Riyadh. The main findings of the present study indicated that more than $79 \%$ of the sampled children skipped daily breakfast with no significant sex differences. Multivariate analyses showed that boys in private schools had significantly higher intake of breakfast than that among boys in public schools; however, boys in public schools had significantly higher BMI than that in boys in private schools. Parents' education and family income significantly influenced 
Table 4 Timing of breakfast consumption and parent's perception of child's breakfast intake

\begin{tabular}{|c|c|c|c|}
\hline \multirow[t]{2}{*}{ Variable (percent within item relative to total) } & \multicolumn{2}{|c|}{ Breakfast Intake (\%) } & \multirow[t]{2}{*}{$p$-value * } \\
\hline & Daily & Non-daily & \\
\hline Time breakfast consumed by the child (\%) & & & 0.311 \\
\hline Before 6:00 am (47.4\%) & 24.8 & 75.2 & \\
\hline After 6:00 am (52.6\%) & 23.1 & 76.9 & \\
\hline Who prepare the breakfast for the child? (\%) & & & 0.039 \\
\hline Mother (84.5\%) & 20.3 & 79.7 & \\
\hline Father $(0.5 \%)$ & 20.0 & 80.0 & \\
\hline Domestic helper (8.6\%) & 33.7 & 66.3 & \\
\hline Sister/brother (3.0\%) & 16.1 & 83.9 & \\
\hline The child himself/herself (2.1\%) & 13.6 & 86.4 & \\
\hline Brought ready from the market $(0.3 \%)$ & 0.0 & 100.0 & \\
\hline Nothing is prepared at home $(0.9 \%)$ & 0.0 & 100.0 & \\
\hline $\begin{array}{l}\text { How much Satisfied with the breakfast consumed } \\
\text { by your child at home? (\%) }\end{array}$ & & & 0.004 \\
\hline Satisfied (40.3\%) & 24.0 & 76.0 & \\
\hline Somewhat happy (47.3\%) & 21.5 & 78.5 & \\
\hline Not satisfied (12.4\%) & 10.3 & 89.7 & \\
\hline $\begin{array}{l}\text { As a meal, how important is your child's breakfast } \\
\text { for you? (\%) }\end{array}$ & & & 0.389 \\
\hline Very important (91.2\%) & 21.4 & 78.6 & \\
\hline Somewhat important (8.0\%) & 15.7 & 84.3 & \\
\hline Not important (0.8\%) & 12.5 & 87.5 & \\
\hline $\begin{array}{l}\text { In your opinion, which is the most important meal } \\
\text { of the day for your child? (\%) }\end{array}$ & & & 0.001 \\
\hline Breakfast (80.2\%) & 23.2 & 76.8 & \\
\hline Lunch (17.7\%) & 12.0 & 88.0 & \\
\hline Dinner (2.1\%) & 4.5 & 95.5 & \\
\hline $\begin{array}{l}\text { How important having enough protein in your } \\
\text { child's breakfast? (\%) }\end{array}$ & & & 0.395 \\
\hline Very important (73.7\%) & 21.3 & 78.7 & \\
\hline Not important (4.5\%) & 29.5 & 70.5 & \\
\hline I do not know (21.8\%) & 20.4 & 79.6 & \\
\hline $\begin{array}{l}\text { Do you think (as a parent) that having breakfast } \\
\text { improves child's academic performance? (\%) }\end{array}$ & & & 0.141 \\
\hline Yes (93.0\%) & 21.4 & 78.6 & \\
\hline No $(0.2 \%)$ & 50.0 & 50.5 & \\
\hline I do not know (6.8\%) & 12.9 & 87.1 & \\
\hline
\end{tabular}

${ }^{*}$ Chi Squares tests of the proportions for significant difference between boys and girls

breakfast consumption. In addition, significant sex by school type interactions were observed.

Comparison of our findings on breakfast skipping with those of earlier local studies revealed many differences. Earlier studies conducted in Saudi school students reported a slightly lower percentage of breakfast skipping by Saudi children than that in the current study [23, 24]. Among Saudi students aged 5-18 years in Jeddah city, the prevalence of breakfast skipping was nearly $15 \%$, and there were no differences relative to age, sex, BMI, or social class. The study also found that breakfast skipping was associated with poor school performance [23]. Besides having been conducted a long time ago, the main focus of the previous study was anemia in school students and used a self-reported questionnaire even in young students aged 9-12 years [23]. In another study conducted in Riyadh city, $16.5 \%$ of the school girls did not eat breakfast at home and relied on snacks from the 
Table 5 Socio-demographic characteristics of the participants relative to daily or non-daily breakfast intake (mean and SD or percentage)

\begin{tabular}{|c|c|c|c|}
\hline \multirow[t]{2}{*}{ Variable (percent within item relative to total) } & \multicolumn{2}{|c|}{ Breakfast Intake } & \multirow[t]{2}{*}{$\boldsymbol{p}$-value ${ }^{a}$} \\
\hline & Daily & Non-daily & \\
\hline Age (years) & $9.1 \pm 1.6$ & $9.3 \pm 1.8$ & 0.266 \\
\hline Body weight (kg) & $34.7 \pm 18.7$ & $36.2 \pm 19.1$ & 0.332 \\
\hline Height (cm) & $132.4 \pm 12.0$ & $133.6 \pm 12.2$ & 0.188 \\
\hline BMI & $19.1 \pm 1.7$ & $19.5 \pm 1.7$ & 0.441 \\
\hline Average breakfast intake (day/week) & 7.0 & $2.7 \pm 1.7$ & $<0.001$ \\
\hline Parent answering the questionnaire (\%) & & & 0.596 \\
\hline Mother (53.5\%) & 21.5 & 78.5 & \\
\hline Father (43.1\%) & 19.6 & 80.4 & \\
\hline Someone else (3.4\%) & 25.7 & 74.3 & \\
\hline
\end{tabular}

The child is living with (\%)

Both parents (94.3\%)

Mother (4.2\%)

Father (1.3\%)

Relative $(0.2 \%)$

Number of family members living in the house (\%)

$10+(6.6 \%)$

Father's age (\%)

Mother's age (\%)

$<30$ years $(8.7 \%)$

$30-39$ years $(54.1 \%)$

Father's education (\%)

High school (32.0\%)

University degree (43.2\%)

Mother's education (\%)

High school (31.9\%)

University degree (46.9\%)

Family income (\%) ${ }^{\text {b }}$ 
Table 5 Socio-demographic characteristics of the participants relative to daily or non-daily breakfast intake (mean and SD or percentage) (Continued)

\begin{tabular}{lll}
\hline Variable (percent within item relative to total) & Breakfast Intake & Non-daily \\
\cline { 2 - 3 } & Daily & 83.8 \\
\hline $5001-10,000$ SR (26.4\%) & 16.2 & 78.9 \\
$10,001-15,000$ SR (25.1\%) & 21.1 & 77.8 \\
$15,001-20,000$ SR (18.3\%) & 22.2 & 63.7 \\
$20,001-25,000$ SR (8.1\%) & 36.3 & 74.7 \\
$25,001+$ SR (8.8\%) & 25.3 & \\
Type of housing living in (\%) & & 83.8 \\
Apartment (19.8\%) & 16.2 & 77.7 \\
One floor in a villa $(28.2 \%)$ & 22.3 & 76.9 \\
Small villa (less than $\left.500 \mathrm{~m}^{2}\right)(26.0 \%)$ & 23.1 & 80.5 \\
Medium size villa $\left(500-1000 \mathrm{~m}^{2}\right)(21.9 \%)$ & 19.5 & 73.8 \\
Large villa (more than $\left.1000 \mathrm{~m}^{2}\right)(4.1 \%)$ & 26.2 & 0.295 \\
\hline
\end{tabular}

${ }^{\mathrm{a} C h i}$-Square tests of proportions

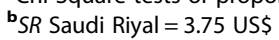

school canteen, which consisted mostly of chocolate bars, biscuits, and potato chips along with soda drinks [24]. Additional differences between our findings regarding breakfast skipping and those of the earlier local studies may also reflect lifestyle changes of Saudi children and adolescents (including nutritional patterns) over the past three decades [25], which is the period between the current and previous studies.

The frequency of regular breakfast consumption by the Saudi children in the present study was lower than that reported in other countries. For an instance, a study involving 41 countries participating in the Health Behavior in School-aged Children (HBSC) study found that daily breakfast consumption among students aged 11-15 year varied from $33 \%$ in Greek girls to $75 \%$ among Portuguese boys [31]. Furthermore, only 30\% of Sri Lankan children consumed breakfast at home [32]. However, different surveys can produce different findings. Contrary to the nonsignificant sex difference in the proportion of daily breakfast intake observed in the present study, female adolescents from neighboring Bahrain [33] skipped breakfast significantly more often than did male adolescents $(62.8 \%$ versus $37.2 \%$ ).

Previous studies have shown that numerous factors can influence breakfast intake, including sex, family structure, and socio-economic status $[2,7,9,34,35]$. Our findings in the present study indicated that there was no significant difference in daily breakfast intake relative to the living status of the child (living with father, mother, or both parents), the number of family members living in the home, or father's or mother's ages. However, research elsewhere revealed that children living with both parents had higher chances of breakfast consumption compared to those living with a single parent $[8,9]$. In addition, a decrease in daily breakfast consumption has been observed in children living in single-parent families [9] and an increase in breakfast intake was shown among children of two-parent families [35]. The difference between our findings and those from other studies may be due to the modest number of single mothers $(4.3 \%)$ or fathers $(1.3 \%)$ in the present study.

In the HBSC study, lower daily breakfast intake was associated with female sex, older adolescents, and living in single-parent families [31]. In the current study, there was no significant difference in the proportions of children consuming daily breakfast relative to sex. However, students in private schools had higher mean breakfast intakes. Children attending private schools had significantly higher parent education and family income levels, which may suggest that highly educated and affluent parents were more likely to have their children consume breakfast at home. In comparison, data from the $\mathrm{Na}$ tional Health and Nutrition Examination Survey of the United States demonstrated that boys consumed daily breakfast more often than girls did [7]. Furthermore, a study with a large number of adolescents from ten European cities reported that the factors most associated with breakfast consumption included girls with highly educated mothers, boys with traditional families, boys encouraged by their parents, and girls whose peers ate healthy diets [10]. In the present study, logistic regression adjusted for confounders showed an insignificant effect of parent education. Nevertheless, parental education was found to influence breakfast intake in European children [34]. Moreover, family income was generally reported to be associated with breakfast consumption in children and adolescents [2]. However, among a group of school children from Riyadh surveyed two decades 
Table 6 Results of logistic regression analysis, adjusted for age, weight and BMI, for selected sociodemographic variables relative to daily versus non-daily breakfast intake among Saudi children

\begin{tabular}{|c|c|c|c|c|}
\hline \multirow[t]{2}{*}{ Variable } & \multicolumn{4}{|c|}{ Daily versus non-daily breakfast intake ${ }^{a}$} \\
\hline & $\mathrm{aOR}$ & $(95 \% \mathrm{Cl})$ & SEE & $p$-value \\
\hline Age & 0.953 & $0.824-1.102$ & .074 & 0.008 \\
\hline Weight & 0.993 & $0.954-1.033$ & 0.020 & 0.717 \\
\hline BMI & 1.017 & $0.928-1.115$ & 0.047 & 0.717 \\
\hline Gender (girls = ref) & 1.00 & & & \\
\hline Boys & 0.830 & $0.582-1.184$ & 0.830 & 0.303 \\
\hline School type (private = ref) & 1.00 & & & \\
\hline Public & 0.874 & $0.582-1.300$ & 0.203 & 0.506 \\
\hline No. of Family member in the house $(\geq 10=$ ref) & 1.00 & & & \\
\hline $6-9$ & 0.716 & $0.352-1.456$ & 0.362 & 0.356 \\
\hline $2-5$ & 0.604 & $0.274-1.329$ & 0.403 & 0.210 \\
\hline Father age $(60+$ years $=$ ref $)$ & 1.00 & & & \\
\hline $50-59$ & 1.756 & $0.477-6.460$ & 0.655 & 0.397 \\
\hline $40-49$ & 1.570 & $0.418-5.889$ & 0.675 & 0.504 \\
\hline $30-39$ & 2.230 & $0.565-8.804$ & 0.701 & 0.252 \\
\hline Mother age $(60+$ years $=$ ref $)$ & 1.00 & & & \\
\hline $50-59$ & 0.047 & $0.003-0.816$ & 1.451 & 0.036 \\
\hline $40-49$ & 0.085 & $0.005-1.331$ & 1.402 & 0.079 \\
\hline $30-39$ & 0.095 & $0.006-1.516$ & 1.412 & 0.096 \\
\hline$<30$ & 0.044 & $0.002-0.770$ & 1.465 & 0.033 \\
\hline Father education (postgraduate $=$ ref) & 1.00 & & & \\
\hline College degree & 0.871 & $0.520-1.465$ & 0.264 & 0.608 \\
\hline High school & 0.551 & $0.301-1.011$ & 0.309 & 0.054 \\
\hline$<$ High school & 0.555 & $0.231-1.331$ & 0.447 & 0.187 \\
\hline Mother education postgraduate $=$ ref) & 1.00 & & & \\
\hline College degree & 1.853 & $0.665-5.167$ & 0.523 & 0.238 \\
\hline High school & 1.399 & $0.481-4.068$ & 0.545 & 0.538 \\
\hline$<$ High school & 2.375 & $0.771-7.323$ & 0.574 & 0.132 \\
\hline Family income $(>25,000=$ ref $)$ & 1.00 & & & \\
\hline $20,001-25,000$ & 1.759 & $0.819-3.779$ & 0.390 & 0.148 \\
\hline $15,001-20,000$ & 1.334 & $0.670-2.655$ & 0.351 & 0.412 \\
\hline $10,001-15,000$ & 1.006 & $0.507-1.999$ & 0.350 & 0.986 \\
\hline $5001-10,000$ & 0.893 & $0.435-1.830$ & 0.366 & 0.786 \\
\hline$\leq 5000$ & 0.798 & $0.332-1.917$ & 0.447 & 0.614 \\
\hline
\end{tabular}

${ }^{a}$ Non-daily breakfast intake was used as a reference category. aOR adjusted odds ratio, $\mathrm{Cl}$ confidence interval, ref. reference category, SEE standard error

ago, there was no association between parents' education and the frequency of breakfast intake at home [24]. Information on demographic and socioeconomic correlates of breakfast intake among children and youth is important for identifying children requiring intervention [36].

In the present study, the most common reasons for Saudi children to not have regular breakfast at home were not feeling hungry and waking up late or having no time to eat breakfast. This could due to the early start of
Saudi schools (7.00 am), leaving little time in the morning before going to school for students who wake late. Most of the sampled children did not get sufficient sleep, as our current study showed that nearly $71 \%$ received less than the minimally recommended sleep duration of $9 \mathrm{~h}$ per night [37]. Similar findings were found among elementary school children in Bangkok, in which the key barriers to breakfast consumption were lack of time, waking late, and lack of breakfast prepared at home [11]. 
Table 7 Results of multivariate analyses of average breakfast intake and body mass index (BMI) stratified by gender and school type, while controlling for confounders (data are mean and SD)

\begin{tabular}{lllll}
\hline Variable & School type & Boys & Girls & $\boldsymbol{p}$-value for between subjects effects \\
\hline Average breakfast intake (day/week) & Public & $3.1 \pm 2.2(2.7-3.4)$ & $3.5 \pm 2.3(3.2-3.9)$ & Gender: 0.414 \\
& Private & $4.3 \pm 2.3(3.6-5.0)$ & $3.7 \pm 2.3(3.2-4.2)$ & $\begin{array}{l}\text { School type: } 0.053 \\
\text { Gender by school type interaction: } \mathbf{0 . 0 0 3}\end{array}$ \\
& Public & $21.8 \pm 11.6(20.1-23.5)$ & $18.1 \pm 4.5(17.4-18.8)$ & \begin{tabular}{l} 
Gender: $<\mathbf{0 . 0 0 1}$ \\
BMI \\
\cline { 2 - 4 }
\end{tabular} \\
& Private & $18.9 \pm 4.8(18.8-20.2)$ & $18.2 \pm 4.3(17.2-19.2)$ & $\begin{array}{l}\text { School type: } 0.229 \\
\text { Gender by school type interaction: } \mathbf{0 . 0 0 1}\end{array}$ \\
\hline
\end{tabular}

$P$-values for multivariate tests: child age: $<0.001$; father age: 0.881 mother age: 0.006 ; father education: 0.054 ; mother education: 0.537 ; family income: 0.041 ; housing size: 0.070 ; gender: $<0.001$; school type: 0.070 ; Gender x school type: $<0.001$

The present study did not find significant differences between daily versus non-daily breakfast consumption relative to body weight or BMI. However, obesity has previously been shown to be associated with skipping breakfast in Saudi adolescents [25, 28]. Elsewhere, daily breakfast intake appeared to offer control over body weight, improve blood lipids profile, and increase levels of physical activity among children aged 2-10 years from eight European countries [38]. Skipping breakfast is also associated with obesity in children and adolescents [1315 ] and with increased risk of type 2 diabetes mellitus [16]. Furthermore, skipping breakfast among children and adolescents is related to increased cardio-metabolic risks, including increased obesity and elevated triglyceride, low-density lipoprotein cholesterol, and low-high density lipoprotein cholesterol levels compared to those in regular breakfast consumers [39]. In addition, numerous recent studies in adults have showed the adverse effects of skipping breakfast on cardiovascular (CV) and metabolic health, including increased risk of type 2 diabetes mellitus independent of lifestyle and baseline levels [40] and metabolic inflexibility as a result of prolonged fasting [41], as well as an association with higher risk of non-coronary and generalized atherosclerosis independent of the presence of conventional CV risk factors [42]. A review paper concluded that, despite the variability of the quality of breakfast within the reviewed studies, children who reported eating breakfast regularly were more likely to have superior nutritional profiles than those in peers who skipped breakfast [2]. Moreover, a multicenter European study involving 1058 adolescents aged 12.517.5 years from ten cities observed lower vitamin $D$ and vitamin $\mathrm{C}$ concentrations in male and female breakfastskippers than those in breakfast consumers [17].

A variety of foods were consumed by the Saudi children in the present study. However, spread cheese sandwiches, followed by fried egg sandwiches and breakfast cereals, were consumed most often. In addition, there were significant differences between boys and girls in breakfast intake preferences. Food choices made by children can be influenced by a complex range of variables. Such factors include family, friends, habit, socioeconomic status, health considerations, food availability, food appeal, food taste, ethical concerns, and wider societal trends. Epidemiological studies have consistently reported that a higher intake of RTE cereals by children is more likely to meet their recommended nutrient intakes $[18,19]$. Furthermore, nearly $50 \%$ of the Spanish population aged 2-24 years eat RTE cereals and their macronutrient profile improved with increasing cereal consumption [20]. A recent systematic review on the benefits of RTE cereals concluded that breakfast cereal consumption was related to higher dietary vitamin and mineral intake and higher healthy eating index and was not linked to increased total energy or sodium intakes [21]. However, breakfast consumption of RTE cereals with high amounts of sugar presents nutritional concerns. In the current study, over $70 \%$ of Saudi children who ate breakfast cereals consumed products with sugar, while less than one-fifth of sample preferred cereals with fruits, without any significant sex differences. This may indicate that not many Saudi children ate healthy breakfast cereals rich in fiber and low in sugar. Furthermore, pizza, hot dogs, and hamburgers were reported as a breakfast choices by less than $10 \%$ of the Saudi children. In comparison, fast foods as a breakfast meal were the most preferred food by Siri Lankan children, followed by wheat flour-based breakfast items [32]. In the present study, Mediterranean food choices like fava beans (Foul) and thyme and falafel sandwiches were fairly consumed during breakfast. Such vegetable-based foods are considered healthy and have high levels of protein, fibers, vitamins, and minerals.

Our findings indicated that most children consumed drinks during breakfast time, with a significantly higher percentage of boys consuming drinks compared to that in girls. Full-fat milk, tea with milk, water, and fruit juice were the drinks most consumed by the children. Girls showed a significantly higher water intake with breakfast than that in boys. A previously published local study found that tea drinking was common among schoolgirls in Riyadh [24]. Moreover, a study involving adolescents aged 12-18 years from the Al Qassim region in central Saudi Arabia, showed contrasting findings in fluid intake between boys and girls during breakfast, with boys more frequently drinking milk and juice compared to girls, while the girls consumed more water compared to boys [26]. The current study also showed that a significantly 
higher percentage of girls consumed fresh fruits with breakfast, especially apples, bananas, oranges, and grapes, compared to that in boys, in contrast to earlier reports involving Saudi school children in Riyadh showing infrequent consumption of fresh fruits and vegetable by girls [24]. This difference may reflect changes over the two decades due to economic growth of the country and purchasing power of the families.

The results of the present study showed that Saudi parents placed very high importance on the breakfast meal of their children and that, compared to lunch and dinner, most parents considered their children's breakfast to be the most important meal of the day. This finding agrees with the results of a study conducted in Siri Lanka, which reported that the mothers of Siri Lankan children considered breakfast to be an essential meal [32]. Furthermore, our results showed a significant trend toward higher daily breakfast intake when parents were satisfied with their children's breakfast and that most parents believed that having breakfast can improve the academic performance of children. This finding agrees with previous research showing that breakfast consumption can improve cognitive learning and academic performance in children [2-6]. Thus, parental knowledge and emphasis on the importance of breakfast consumption were not lacking among most of the Saudi parents in the present study. However, a previous report recommended working with children, parents, and schools to generate positive knowledge and beliefs about breakfast consumption that might be beneficial in increasing the rate of breakfast intake among children [43].

Finally, this study has its strengths and limitations. The strengths include the large and representative sample of Saudi children from both public and private schools. However, the limitations of the current study include its cross-sectional design, which precludes us from determining a causal relationship between breakfast intake and respective variables. In addition, breakfast consumption and behaviors were assessed using a questionnaire completed by the child's parent. Questionnaires are generally subject to recall bias and social desirability effects. Finally, although Riyadh is a cosmopolitan city with people from all parts of the country, the breakfast choices and preferences of the children in the present study may not exactly reflect those of children in other parts of the country, especially in rural areas.

\section{Conclusions}

The present study revealed that about one-fifth of the sampled children consumed breakfast daily, with no significant difference between boys and girls. Children in private schools, however, consumed daily breakfast significantly more frequently than those children in public schools. Multivariate analyses showed that boys in private schools had a significantly higher intake of breakfast than that in boys in public schools, yet boys in public schools had a significantly higher BMI than that in boys in private schools. Using logistic regression while adjusting for confounders showed an insignificant effect of parent education. Spread cheese sandwich followed by fried egg sandwich and breakfast cereals were consumed most often by Saudi school children. Further, full-fat milk, tea with milk, water, and fruit juice were the drinks most consumed by the children. Girls consumed significantly more fresh fruits at breakfast than did boys. In addition, mothers generally prepared breakfast at home. There was a significant trend toward higher daily breakfast intake when parents were satisfied with their children's breakfast. Parents also placed very high importance on breakfast compared to lunch or dinner. Overall, breakfast is a healthy and important dietary habit that is worth maintaining by school children. However, the proportion of Saudi children who skipped daily breakfast at home was high, which may have implications for their academic performance. Therefore, a concerted effort is needed to promote daily breakfast consumption among Saudi school children. Future studies may need to address the psychological, cultural, and environmental correlates associated with breakfast consumption among Saudi children. The introduction of appropriate interventions is also recommended to promote daily breakfast consumption among Saudi children.

\section{Supplementary information}

Supplementary information accompanies this paper at https://doi.org/10 1186/s12889-020-8418-1.

Additional file 1. Breakfast eating habits and behaviors questionnaire. The questionnaire was developed by the authors and included items related to breakfast eating habits, food choices, and behaviors. The questionnaire also included information on demographic and socioeconomic status.

\section{Abbreviations}

ANCOVA: Analysis of covariance; BMl: Body mass index; CV: Cardiovascular; HBSC: Health behavior in school-aged children; MANCOVA: Multivariate analysis of covariance; RTE: Ready-to-eat (RTE) cereals

\section{Acknowledgements \\ Thanks to the research assistants who helped in the data collection. Appreciation is also extended to all the children and their parents who agreed to take part in this study.}

Authors' contributions

Study concept and design: HMA and OAO; data collection: HMA, AMA, and $M H A$; statistical analysis: HMA; findings interpretation: $\mathrm{HMA}, \mathrm{OAO}, \mathrm{AMA}$, and MHA; paper drafting: HMA. All authors critically read and approved the final draft.

\section{Funding}

This research was supported by a grant from Kellogg's company; however, there were no other relationships or activities that could have influenced the submitted work. The funder had no role in the study design, data collection, analysis, interpretation, or drafting of the manuscript. Additional funding towards the preparation of this manuscript was provided by the Deanship of 
Scientific Research at Princess Nourah bint Abdulrahman University through the Fast-track Research Funding Program.

\section{Availability of data and materials}

All data generated or analyzed during this study are included in this published article. Any additional data are available from the corresponding author on reasonable request.

\section{Ethics approval and consent to participate}

Ethical approval was obtained from the Institutional Review Board (IRB) at King Saud University (17/0064/IRB). The research procedures were conducted in accordance with the principles expressed in the Declaration of Helsinki. Written informed consent was obtained from all parents. Approval for conducting this research in schools was obtained from the directorate of schools at the Ministry of Education and the principals of the selected schools.

\section{Consent for publication}

\section{Not applicable.}

\section{Competing interests}

The authors declare that they have no competing interests.

\begin{abstract}
Author details
${ }^{1}$ Lifestyle and Health Research Center, Health Science Research Center, Princess Nourah bint Abdulrahman University, P. O. Box: 93216, Riyadh 11673, Saudi Arabia. ${ }^{2}$ Department of Physiology, Faculty of Medicine, King Saud University, Riyadh, Saudi Arabia. ${ }^{3}$ Department of Food Science \& Nutrition, College of Food \& Agricultural Sciences, King Saud University, Riyadh, Saudi Arabia. ${ }^{4}$ Department of Human Nutrition and Food Sciences, American University of Beirut, Beirut, Lebanon.
\end{abstract}

\section{Received: 14 July 2019 Accepted: 26 February 2020}

\section{Published online: 06 April 2020}

\section{References}

1. Rampersaud G. Benefits of breakfast for children and adolescents: update and recommendations for practitioners. Am J Lifestyle Med. 2009;3(2):86-103.

2. Rampersaud GC, Pereira MA, Girard BL, Adams J, Metzl JD. Breakfast habits, nutritional status, body weight, and academic performance in children and adolescents. J Am Diet Assoc. 2005;105:743-60.

3. Adolphus K, Lawton CL, Dye L. The effects of breakfast on behavior and academic performance in children and adolescents. Front Hum Neurosci. 2013;7:425. https://doi.org/10.3389/fnhum.2013.00425 eCollection 2013.

4. Widenhorn-Müller K, Hille K, Klenk J, Weiland U. Influence of having breakfast on cognitive performance and mood in 13- to 20-year-old high school students: results of a crossover trial. Pediatrics. 2008;122:279-84.

5. Basch CE. Breakfast and the achievement gap among urban minority youth. Sch Health. 2001:81:635-40. https://doi.org/10.1111/j.1746-1561.2011.00638x.

6. Ptomey LT, Steger FL, Schubert MM, Lee J, Willis EA, Sullivan DK, et al. Breakfast intake and composition is associated with superior academic achievement in elementary schoolchildren. J Am Coll Nutr. 2016:35:326-33.

7. Deshmukh-Taskar PR, Nicklas TA, O'Neil CE, Keast DR, Radcliffe JD, et al. The relationship of breakfast skipping and type of breakfast consumption with nutrient intake and weight status in children and adolescents: the National Health and nutrition examination survey 1999-2006. J Am Diet Assoc. 2010; 110:869-78.

8. Pearson N, Biddle SJH, Gorely T. Family correlates of breakfast consumption among children and adolescents. A systematic review. Appetite. 2009;52:1-7.

9. Levin K, Kirby J, Currie C. Family structure and breakfast consumption of 1115 year old boys and girls in Scotland, 1994-2010: a repeated cross-sectional study. BMC Public Health. 2012;12:228.

10. Hallström L, Vereecken CA, Ruiz JR, Patterson E, Gilbert CC, Catasta G, et al. Breakfast habits and factors influencing food choices at breakfast in relation to socio-demographic and family factors among European adolescents. The HELENA Study. Appetite. 2011;56:649-57.

11. Sirichakwal PP, Janesiripanich N, Kunapun P, Senaprom S, Purttipornthanee S. Breakfast consumption behaviors of elementary school children in Bangkok metropolitan region. Southeast Asian J Trop Med Public Health. 2015:46:939-48.
12. Affenito SG, Thompson DR, Barton BA, Franko DL, Daniels SR, Obarzanek E, et al. Breakfast consumption by African-American and white adolescent girls correlates positively with calcium and fiber intake and negatively with body mass index. J Am Diet Assoc. 2005:105:938-45.

13. Dubois L, Girard M, Potvin KM. Breakfast eating and overweight in a preschool population: is there a link? Public Health Nutr. 2006:9:436-42.

14. Kyriazis I, Rekleiti M, Saridi M, Beliotis E, Toska A, Souliotis K, et al. Prevalence of obesity in children aged 6-12 years in Greece: nutritional behaviour and physical activity. Arch Med Sci. 2012;8:859-64. https://doi.org/10.5114/aoms. 2012.31296.

15. Watanabe Y, Saito I, Henmi I, Yoshimura K, Maruyama K, Yamauchi K, et al. Skipping breakfast is correlated with obesity. J Rural Med. 2014;9:51-8.

16. Bi H, Gan Y, Yang C, Chen Y, Tong X, Lu Z, et al. Breakfast skipping and the risk of type 2 diabetes: a meta-analysis of observational studies. Public Health Nutr. 2015:18:3013-9.

17. Mielgo-Ayuso J, Valtueña J, Cuenca-García M, Gottrand F, Breidenassel C, Ferrari $\mathrm{M}$, et al. Regular breakfast consumption is associated with higher blood vitamin status in adolescents: the HELENA (healthy lifestyle in Europe by nutrition in adolescence) study. Public Health Nutr. 2017;20:1393-404.

18. Albertson AM, Affenito SG, Bauserman R, Holschuh NM, Eldridge AL, Barton $\mathrm{BA}$, et al. The relationship of ready-to-eat cereal consumption to nutrient intake, blood lipids, and body mass index of children as they age through adolescence. J Am Diet Assoc. 2009;109:1557-65.

19. Montenegro-Bethancourt G, Vossenaar M, Kuijper LD, Doak CM, Solomons NW. Ready-to-eat cereals are key sources of selected micronutrients among schoolchildren from public and private elementary schools in Quetzaltenango. Guatemala Nutr Res. 2009:29:335-42.

20. van den Boom A, Serra-Majem L, Ribas L, Ngo J, Pérez-Rodrigo C, Aranceta $J$, et al. The contribution of ready-to-eat cereals to daily nutrient intake and breakfast quality in a Mediterranean setting. J Am Coll Nutr. 2006;25:135-43.

21. Williams PG. The benefits of breakfast cereal consumption: a systematic review of the evidence base. Adv Nutr. 2014:5:S636-S73.

22. Harris JL, Schwartz MB, Ustjanauskas A, Ohri-Vachaspati P, Brownell KD. Effects of serving high-sugar cereals on children's breakfast-eating behavior. Pediatrics. 2011;127:71-6.

23. Abalkhail B, Shawky S. Prevalence of daily breakfast intake, iron deficiency anaemia and awareness of being anaemic among Saudi school students. Int J Food Sci Nutr. 2002:53:519-28.

24. al-Othaimeen $\mathrm{A}$, et al. Prevalence of nutritional anaemia among primary school girls in Riyadh City, Saudi Arabia. Int J Food Sci Nutr. 1999:50:237-43.

25. Al-Hazzaa HM, Abahussain N, Al-Sobayel H. Qahwaji DM, Musaiger AO. Physical activity, sedentary behaviors and dietary habits among Saudi adolescents relative to age, Gender and Region, Int J Behav Nutr Phys Act 2011; 8, 140.

26. Aldulaylan S. Food choices among adolescent girls and boys in intermediate and secondary schools in Al Qassim, Saudi Arabia. Lubbock: A Master Thesis, Texas Tech University; 2016.

27. Agostoni C, Brighenti F. Dietary choices for breakfast in children and adolescents. Crit Rev Food Sci Nutr. 2010;50:120-8.

28. Al-Hazzaa HM, Abahussain NA, Al-Sobayel HI, Qahwaji DM, Musaiger AO. Lifestyle factors associated with overweight and obesity among Saudi adolescents. BMC Public Health. 2012;12:354.

29. Al-Hazzaa HM, Musaiger AO, Abahussain N, Al-Sobayel H, Qahwaji DM. Lifestyle correlates of self-reported sleep duration among Saudi adolescents: a multicenter school-based cross-sectional study. Child Care Health Dev. 2014:40:533-42.

30. Al-Hazzaa HM, Alhussain MH, Alhowikan AM, Obeid OA. Insufficient sleep duration and its association with breakfast intake, overweight/obesity, sociodemographics and selected lifestyle behaviors among Saudi school children. Nat Sci Sleep. 2019:11:253-63.

31. Vereecken C, Dupuy M, Rasmussen M, Kelly C, Nansel TR, Al Sabbah H, et al. Breakfast consumption and its socio-demographic and lifestyle correlates in schoolchildren in 41 countries participating in the HBSC study. Int J Public Health. 2009;54(Suppl 2):180-90.

32. Senanayake MP, Parakramadasa HM. A survey of breakfast practices of 4-12 year old children. Sri Lanka J of Child Health. 2008;37:112-7 http://192.24 8.16.117:8080/research/bitstream/70130/2016/1/mano11.pdf.

33. Musaiger AO, Bader Z, Al-Roomi K, D'Souza R. Dietary and lifestyle habits amongst adolescents in Bahrain. Food Nutr Res. 2011;55. https://doi.org/10. 3402/fnr.v55i0.7122.

34. Manios Y, Moschonis G, Androutsos O, Filippou C, Van Lippevelde W, Vik FN, et al. Family sociodemographic characteristics as correlates of children's 
breakfast habits and weight status in eight European countries. The ENERGY (EuropeaN Energy balance research to prevent excessive weight gain among youth) project. Public Health Nutr. 2015;18:774-83.

35. Timlin MT, Pereira MA, Story M, Neumark-Sztainer D. Breakfast eating and weight change in a 5-year prospective analysis of adolescents: project EAT (eating among teens). Pediatrics. 2008;121:E638-45.

36. Giacomo L, Ahluwalia N, Niclasen B, Pammolli A, Vereecken C, Rasmussen M, et al. Trends from 2002 to 2010 in daily breakfast consumption and its socio-demographic correlates in adolescents across 31 countries participating in the HBSC study. PLoS One. 2016;11(3):e0151052.

37. Hirshkowitz M, Whiton K, Albert SM, Alessi C, Bruni O, DonCarlos L, et al. National Sleep Foundation's sleep time duration recommendations: methodology and results summary. Sleep Health. 2015;1:40-3.

38. Papoutsou S, Briassoulis G, Wolters M, Peplies J, lacoviello L, Eiben G, et al. No breakfast at home: association with cardiovascular disease risk factors in childhood. Eur J Clin Nutr. 2014;68:829-34.

39. Shafiee G, Kelishadi R, Qorbani M, Motlagh ME, Taheri M, Ardalan G, et al. Association of breakfast intake with cardiometabolic risk factors. J Pediatr. 2013;89:575-82.

40. Uemura M, Yatsuya H, Hilawe EH, Li Y, Wang C, Chiang C, et al. Breakfast skipping is positively associated with incidence of type 2 diabetes mellitus: evidence from the Aichi Workers' cohort study. J Epidemiol. 2015;25:351-8.

41. Nas A, Mirza N, Hägele F, Kahlhöfer J, Keller J, Rising R, et al. Impact of breakfast skipping compared with dinner skipping on regulation of energy balance and metabolic risk. Am J Clin Nutr. 2017;105:1351-61. https://doi. org/10.3945/ajcn.116.151332

42. Uzhova I, Fuster V, Fernández-Ortiz A, Ordovás JM, Sanz J, Fernández-Friera $L$, et al. The importance of breakfast in atherosclerosis disease: insights from the PESA study. J Am Coll Cardiol. 2017;70:1833-42.

43. Cheng TS, Tse LA, Yu IT, Griffiths S. Children's perceptions of parental attitude affecting breakfast skipping in primary sixth-grade students. J Sch Health. 2008;78:203-8.

\section{Publisher's Note}

Springer Nature remains neutral with regard to jurisdictional claims in published maps and institutional affiliations.

Ready to submit your research? Choose BMC and benefit from:

- fast, convenient online submission

- thorough peer review by experienced researchers in your field

- rapid publication on acceptance

- support for research data, including large and complex data types

- gold Open Access which fosters wider collaboration and increased citations

- maximum visibility for your research: over $100 \mathrm{M}$ website views per year

At $\mathrm{BMC}$, research is always in progress.

Learn more biomedcentral.com/submissions 